\title{
Spectrum
}

een voorziening onder regie van de gemeente. De inhoud, beschikbaarheid en reikwijdte van jeugdhulp wordt bepaald door lokale democratische besluitvorming (Raad voor het Openbaar Bestuur). Periodiek moeten 408 gemeenten een plan maken voor de jeugdhulp. Omwille van de 'overbodige' medicalisering zijn de ingrediënten: voorkomen en vroegsignalering, opvoedondersteuning en het versterken van de eigen mogelijkheden, vanuit de visie van de pedagogische civil society.

De enige manier om daar invloed te veranderen is via de gemeenteraadsverkiezingen. Verhuizen is een andere optie, in een gemeente gaan wonen die meer biedt.

\section{SPECIALISTISCHE ZORG}

In de toelichting bij de jeugdwet wordt erkend dat soms zwaardere vormen van hulp en zorg nodig zullen blijven. In dat geval wordt een snelle en goede toeleiding nodig geacht. Ook staatsecretaris van Rijn benadrukte dat begin juli in het NRC. Daarom zouden de huisarts, de jeugdarts en de medisch specialist kunnen verwijzen naar de jeugd ggz.

Kan ik dan zoals nu via de huisarts verwezen worden? Nee. De gemeente kan in een verordening aangeven welke vormen van jeugdhulp na verwijzing mogelijk zijn, alsook de voorwaarden .

Een gemeente is er bovendien enkel toe gehouden een voorziening te treffen "als de jeugdige en zijn ouders er op eigen kracht niet uitkomen.” In een gesprek met de jeugdige, de ouders en het sociale netwerk zal dat worden getoetst. Als er vervolgens jeugdhulp nodig is, dan "beslist de gemeente of en welke voorziening een jeugdige nodig heeft."

\section{De GEMEENTE CENTRAAL}

Geheel in lijn met de jeugdwet heeft de regio Peel en Maas de gezinscoach ingevoerd. Die gaat volgens het principe van 1gezin/1plan, gebruik makend van de eigen kracht, doelen opstellen. Waar nodig wordt specialistische hulp ingeroepen. De gezinscoach blijft de centrale persoon die bewaakt of de doelen worden behaald, of iedereen in het gezin betrokken is en of de afspraken worden nagekomen.

De jeugdwet heeft als doel de zorg eenvoudiger te maken. Met dat doel wordt de indicatie door Bureau Jeugdzorg afgeschaft. In de nieuwe context wordt Bureau Jeugdzorg gewoon vervangen door een gezinscoach. Een overbodige bureaucratische laag wordt aldus in stand gehouden. Als wij voor eventuele psychische problemen van onze zoon zorg nodig hebben, dan wordt de gezinscoach een verplichte en overbodige tussenkomst. Ons ouders wordt de regie ontnomen.

\section{TROOST}

Als we het als ouders niet eens zijn met de uitkomsten van het gesprek met 'de gemeente' dan rest ons één mogelijkheid.

Conform de Algemene Wet Bestuursrecht kunnen we bezwaar en beroep aantekenen. 'Daarmee is de rechtsbescherming van de burger gewaarborgd.'

De private sector gaat vast gouden tijden beleven (voor wie het kan betalen), tot ook deze jeugdwet weer herzien wordt. Hopelijk blijven de gevolgen voor gezinnen en kinderen beperkt. Anders zal de maatschappij een serieuze prijs betalen.

\section{CORRESPONDENTIEADRES}

Prof. dr. Robert Vermeiren, Endegeesterstraatweg 27, 2342 AK Oegstgeest, e-mail:

R.R.J.M.Vermeiren@curium.nl

\section{Veiligheid van kinderen; zorgen en kansen in de transformatie van de zorg}

\author{
E.J. Knorth, ${ }^{1}$ S.A. Reijneveld ${ }^{2}$
}

Geschat wordt dat in Nederland in 2010 bijna 119.000 minderjarigen bloot stonden aan kindermishandeling, dat is 3,4\% van alle kinderen. Bij de 12-17 jarigen lag het aantal beduidend hoger; 9,9\%. Onveiligheid voor kinderen is met andere woorden overal om ons heen aanwezig. Te verwachten is dat het percentage zal stijgen omdat professionals alerter lijken te worden. ${ }^{1}$ Grote vraag is hoe we grip houden op dit grote en groeiende probleem in het veranderende landschap van zorg voor jeugd. En bij voorkeur: hoe gaan we het beter doen? Daar valt nog wat te doen.

\footnotetext{
Afdeling Orthopedagogiek, RU Groningen

2 Afdeling Gezondheidswetenschappen, UMC Groningen
}

\section{EEN CASUS ALS VOORBEELD}

Bureau Jeugdzorg heeft een melding ontvangen van een leerkracht op een basisschool die zich zorgen maakt over Diana uit groep drie. Het gezin is bekend bij Bureau Jeugdzorg en het maatschappelijk werk, maar er was de afgelopen drie jaar geen bemoeienis met het gezin.

Het gezin woont in een gehuurde flat in een arme buurt. De flat is redelijk schoon en is ingericht met eenvoudig meubilair. Het gezin zit in financiële moeilijkheden sinds de zaak die vader opende failliet ging.

Op school is Diana stilletjes. Ze gaat weinig om met andere kinderen. De lerares meldt dat Diana's cognitieve ontwikkeling achterligt op die van haar leeftijdgenoten, dat Diana in de pauze regelmatig andere kinderen slaat en dat ze verschillende keren onverklaarbare woede-uitbarstingen heeft gehad. De school- 
psycholoog en de klassen-assistent hebben geprobeerd om een vertrouwensband met haar op te bouwen, maar Diana weigerde hun vragen te beantwoorden.

De lerares vertelde dat Diana blauwe plekken heeft gehad op haar handen en rug. Afgelopen half jaar kwam Diana bovendien een keer op school met een gebroken arm en een andere keer met een schouder uit de kom.

Wordt er in Nederland 'gemakkelijk' gemeld bij signalen van kindermishandeling of zijn we relatief terughoudend? Dat weten we niet. We zien het aantal meldingen door professionals de laatste jaren duidelijk toenemen, ${ }^{1}$ maar hebben reden te veronderstellen dat signalen ook nog geregeld worden gemist. Mede tegen deze achtergrond zijn in ons land 'meldcodes' voor professionals geïntroduceerd: richtlijnen hoe te handelen bij een vermoeden van kindermishandeling en huiselijk geweld. Alhoewel er aanwijzingen zijn dat een meldcode hulpverleners er vaker toe aanzet bij 'vermoedens' in actie te komen dan collega's die geen meldcode hanteren garanderen zij allerminst een consistente gedragslijn.

Bovenstaande casusbeschrijving legden we, in veel uitgebreider vorm, recent voor aan ruim 200 professionals, werkzaam bij zes Bureaus Jeugdzorg in Nederland; professionals die wekelijks geconfronteerd worden met mishandelingszaken. ${ }^{2}$ De vraag was a. hoe risicovol de situatie werd geacht voor het beschreven kind, en $b$. wat er diende te gebeuren. Wat betreft de eerste vraag was er een hoge tot flinke mate van overeenstemming. Op het punt van te ondernemen actie was er echter minder consensus: $2 / 3$ deel van de respondenten opteerde voor hulp aan/in het gezin, 1/3 deel adviseerde plaatsing van het kind in een pleeggezin.

De variatie tussen professionals die we vonden is geen uniek resultaat: beslissingen van professionals om al dan niet actie te ondernemen verschillen. ${ }^{3}$ Deze verschillen hangen samen met kenmerken van professionals zelf (ervaring, attituden), van de organisatie waarbinnen men werkt (beleid, ondersteuning), en van de culturele/regionale context (regelgeving, beschikbare zorgvoorzieningen). ${ }^{3,4}$

Nu we aan de vooravond staan van een transformatie van de zorg voor jeugd, waarbij beoogd wordt dat de eerstelijns voorzieningen (zoals huisarts, CJG, GGD, maatschappelijk werk) méér opgroei- en opvoedingsproblemen zélf tot een oplossing brengen en minder doorverwijzen naar specialistische zorg, rijst de vraag wat dit betekent voor de signalering en aanpak van kindermishandeling. Wordt de professional beter toegerust?
Wordt zijn organisatorische inbedding beter? En misschien nog belangrijker: gaat de civil society dergelijke problemen beter voorkomen en oplossen zodat de werklast van professional en diens organisatie minder wordt?

We zijn er niet gerust op. Er komt nog meer druk op het 'voorveld' te staan dan reeds het geval is. ${ }^{5}$ We willen er dan ook voor pleiten dat eerstelijnswerkers ruimte houden/krijgen zich te bekwamen in het signaleren en aanpakken van (vermoedens van) kindermishandeling, met speciale aandacht voor de wijze waarop zij tot het besluit komen al dan niet in actie te komen. Samenwerking met regionale meldpunten voor huiselijk geweld en kindermishandeling ligt in de rede. Er valt veel te winnen in de transformatie van de zorg voor jeugd - maar er valt ook veel te verliezen.

\section{LITERATUUR}

1. Alink L, Pannebakker F, IJzendoorn R van, Bakermans-Kranenburg $M$, Vogels $T$, Euser $S$. Kindermishandeling in Nederland anno 2010: De Tweede Nationale Prevalentiestudie Mishandeling Kinderen en Jeugdigen (NPM-2010). Tijdschr Gezondheidswet 2013;91:xx-xx.

2. Knorth EJ, Koopmans AC, López M. Besluitvorming bij verdenking van kindermishandeling. Paper Kenniskring 'Entree van zorg voor jeugd', Groningen: Academische Werkplaats C4Youth, UMCG, Groningen, 2012. Zie: http:// www.c4youth.nl/actueel/nieuws/nieuwsbericht/_nieuws/ item/detail/c4youth-kenniskring-kindermishandeling-vanafwachten-tot-uithuisplaatsen-1/

3. Arad-Davidson B, Benbenishty R. Contribution of child protection workers' attitudes to their risk assessments and intervention recommendations: A study in Israel. Health Soc Care Community 2009;18:1-9.

4. Theunissen $M H$, Vogels $A G$, Reijneveld SA. Work experience and style explain variation among pediatricians in the detection of children with psychosocial problems. Acad Pediatrics 2012; 2:495-501.

5. Eijk $L M$ van, Verhage V, Noordik FW, Reijneveld SA, Knorth EJ. TakeCare Provincie Groningen. Een onderzoek naar kenmerken van jeugdigen en hun ouders in relatie tot de geboden zorg. Groningen: Universitair Medisch Centrum Groningen / Rijksuniversiteit Groningen, 2013.

\section{Correspondentieadres}

Prof.dr. Erik J. Knorth, Afdeling Orthopedagogiek, RU Groningen, Groningen, e-mail: e.j.knorth@rug.nl 